\title{
The Influence of $k$-Constant to Delay Performance of RI-MAC Protocol for Wireless Sensor Networks
}

\author{
Yueh-Tiam Yong1 ${ }^{1} \cdot$ Chong Eng Tan ${ }^{1} \cdot$ Kartinah bt Hj Zen $^{1}$
}

(C) Springer Science+Business Media New York 2017

\begin{abstract}
In this paper, we introduce a new method to improve the delay performance of RI-MAC protocol, that was originated from the basic concept of IEEE 802.11e EDCA. The delay issue is critical in wireless sensor network (WSN) because it brings up other issues such as energy wastage and limiting its applications. Therefore, the parameter that determine the delay performance, the BeaconTimeout of the RI-MAC protocol will need to be further optimized in order to achieve better delay performance particularly in applications that involved long transmission range. Hence, we introduce the $k$ constant to go with the conventional RI-MAC protocol in order to achieve that. We first evaluate the delay performance of the conventional RI-MAC in long transmission range application focuses on range from 250 to $850 \mathrm{~m}$. The performance evaluation has been carried out through computer simulation of WSN where the relationship and the influence of the proposed $k$ constant in relation to different transmission ranges are also determined. The reason to focus on extended transmission range is to enable wider physical coverage of WSN to use even lesser sensor nodes for better implementation cost effectiveness. The significance of this paper is to highlight that by applying an optimized $k$ constant, the delay performance of the overall network can be maintained at its optimum level.
\end{abstract}

Keywords Wireless sensor network - Long transmission range $\cdot$ Lower node density $\cdot$ Wider coverage $\cdot$ Cost effectiveness $\cdot$ Delay performance

Yueh-Tiam Yong

yuehtiam@yahoo.com

Chong Eng Tan

cetan@unimas.my

Kartinah bt Hj Zen

kartinah@unimas.my

1 Faculty of Computer Science and Information Technology, University Malaysia Sarawak, Kuching, Malaysia 